1 Universidade de Brasília (UnB), Programa de PósGraduação em Bioética - Brasília (DF), Brasil. Orcid: https://orcid. org/0000-0003-49562314

paranhos.denise@uol.com.br

2 Universidade de Brasília (UnB), Programa de PósGraduação em Bioética - Brasília (DF), Brasil. Orcid: https://orcid. org/0000-0002-46404102

edinalda@gmail.com

3 Universidade de Brasília (UnB), Programa de PósGraduação em Bioética - Brasília (DF), Brasil. Orcid: https://orcid. org/0000-0002-02938460

monsores@unb.br

${ }^{4}$ Universidade de Brasília (UnB), Programa de PósGraduação em Bioética

- Brasília (DF), Brasil.

Orcid: https://orcid.

org/0000-0002-46562485

garrafavolnei@gmail.com

\section{As teorias da justiça, de John Rawls e Norman Daniels, aplicadas à saúde}

\author{
The theories of justice, of John Rawls and Norman Daniels, applied to \\ health
}

Denise Gonçalves de Araújo Mello e Paranhos', Edinalda Araújo Matias², Natan Monsores³,

Volnei Garrafa4

DOI: 10.1590/0103-1104201811917

RESUMO O objetivo deste artigo é analisar as teorias de justiça formuladas por John Rawls e Norman Daniels e sua aplicabilidade à saúde. Rawls parte da concepção de que a distribuição de recursos deve ocorrer em duas etapas. Na primeira, a preocupação seria a distribuição igual de direitos e deveres básicos. Na segunda, a partir do princípio da diferença, seriam compensadas as desigualdades injustas, garantindo-se a todos iguais oportunidades. Seu foco foi a distribuição dos bens primários sociais essenciais, não incluindo a saúde, considerada 'bem primário natural'. Daniels adaptou a teoria rawlsiana, estendendo-a à saúde. A teoria de Daniels, ao abarcar a saúde em seu sentido amplo e com status moral especial a ser protegido pelos princípios de liberdade, diferença e igualdade de oportunidades, fortalece a teoria de Rawls. Metodologicamente, trata-se de estudo puramente teórico, desenvolvido a partir de levantamento de literatura. Concluiu-se que, apesar de não apresentarem uma resposta definitiva sobre como distribuir recursos de forma justa, as teorias apresentadas trazem reflexões sobre a necessidade de se reduzirem injustas desigualdades em saúde, bem como suscitam debates sobre questões como cooperação social, liberdades, as bases da igualdade, alocação de recursos escassos, distribuição adequada de rendas e riquezas e de oportunidades.

PALAVRAS-CHAVE Justiça social. Equidade em saúde. Saúde pública.

\begin{abstract}
The aim of this article is to analyze the theories of justice formulated by John Rawls and Norman Daniels and their applicability to health. Rawls proposes that the distribution of resources must occur in two stages. Firstly, the concern would be the equal distribution of basic rights and responsibilities. Secondly, according to the principle of difference, unjust inequalities would be compensated for, in order to ensure everyone equal opportunities. His focus was the distribution of primary social goods, which don't include health, considered a 'natural primary good'. Daniels adapted the Rawlsian theory, extending it to health. Daniels's theory, by embracing health in its broad sense and with special moral status to be protected by the principles of freedom, difference and equality of opportunity, strengthens Rawls's theory. Methodologically, it is a purely theoretical study, developed from a literature survey. It was concluded that, although the authors do not present a definitive solution on how to distribute resources fairly, their theories lead to reflections about the need to reduce unfair inequalities in health, as well as give rise to debates on issues such as social cooperation, freedoms, equality, allocation of scarce resources, adequate distribution of income and wealth and opportunities.
\end{abstract}

KEYWORDS Social justice. Equity in health. Public health. 


\section{Introdução}

O debate sobre o tema 'Justiça', embora antigo, continua atual, e sobre ele ainda não se chegou a um consenso. Na disputa entre interesses diversos, a balança da justiça haverá de pender sempre para um dos lados, o que coloca em xeque, paradoxalmente, a própria noção de justo. Decisões acerca de questões cotidianas diversas suscitam tomadas de posição (sejam elas no campo econômico, político, da saúde ou da educação), e as respostas a essas demandas são essenciais para pôr fim às discussões e garantir avanços sociais.

No presente artigo, a preocupação central foi de investigar a existência de critérios justos para a distribuição de saúde, a partir das teorias de justiça apresentadas por John Rawls e Norman Daniels, sobretudo no aspecto da justiça como equidade. A partir da proposta de um modelo de justiça ancorado nas bases primárias da sociedade, esses dois autores desenvolveram ideias sobre o justo (os princípios da justiça) que entendem devam estar presentes nas instituições, uma vez que seriam elas as intermediadoras entre as pessoas no convívio social.

Rawls ${ }^{\mathbf{1}}$ parte da concepção de que a distribuição de recursos deve ocorrer em duas etapas. Na primeira, a preocupação seria com a distribuição igual de direitos e deveres básicos. Na segunda, a partir do princípio da diferença, seriam compensadas as desigualdades injustas, particularmente aquelas que atingissem os mais desfavorecidos, garantindo-se a todos iguais oportunidades. Na teoria desenvolvida por Rawls, sua preocupação se fundou na distribuição dos bens primários sociais essenciais, considerados por ele como sendo: a liberdade, a oportunidade, a renda, a riqueza e as bases do autorrespeito. A saúde foi concebida por ele como um bem primário natural, que seria distribuído a contento em uma sociedade em que as bases da justiça estivessem solidamente estabelecidas. Por isso, saúde, para Rawls, seria consequência de uma sociedade justa, razão pela qual alega que a discussão sobre os seus efeitos distributivos seria irrelevante.
A partir da teoria da justiça como equidade, de Rawls, Daniels ${ }^{2}$ ampliou a visão sobre a saúde e, relacionando-a ao princípio da oportunidade, desenvolveu uma teoria na qual destacou a importância moral da saúde, em virtude de seu impacto nas oportunidades de vida das pessoas. Nessa linha de raciocínio, apresenta uma reflexão específica acerca do que seja justiça em saúde e busca responder a questões relacionadas ao status da saúde, à possibilidade de se admitirem injustiças em saúde e às formas de se distribuírem recursos em saúde de forma justa.

O objetivo da pesquisa, portanto, foi analisar as teorias da justiça formuladas por John Rawls e Norman Daniels, discutindo a sua aplicação no campo da saúde. Sob o prisma metodológico, trata-se de estudo puramente teórico, sem experimento ou trabalho de campo, que, a partir da literatura sobre o tema, fundamentou-se, num primeiro momento, na análise dos aspectos gerais da teoria da justiça, de Rawls, passando, em seguida, às especificidades por ele trabalhadas com relação aos princípios da diferença e da oportunidade, até chegar à análise da possível aplicação de sua teoria à saúde. Posteriormente, procedeu-se ao exame da teoria de justiça desenvolvido por Daniels, sua relação com a teoria de Rawls e as reflexões por ele apresentadas na busca de aplicação de critérios mais justos na saúde, especialmente no que diz respeito à alocação de recursos. Passa-se, assim, à análise da teoria da justiça, de Rawls.

\section{A teoria da justiça, de John Rawls}

Insatisfeito com os argumentos filosóficos tradicionais acerca da justiça das instituições, bem como sobre o que justifica as ações políticas e sociais, Rawls buscou estabelecer uma justiça social racional a partir de um contrato social hipotético. A reflexão do autor' ${ }^{1}$ parte de uma pergunta inicial: caso houvesse uma aproximação contratual, baseada em um acordo 
tácito entre os membros de uma sociedade colocados em posição de igualdade, e todos pudessem entrar em sintonia, que tipo de providência estaria dentro do senso comum?

Em sua obra, o filósofo argumenta que uma maneira de se pensar a justiça é se perguntar quais princípios básicos seriam por todos aceitos em uma situação de igualdade. Árdua tarefa, tendo em vista que escolhas tais são sempre influenciadas por nossas crenças políticas e religiosas, nossa posição social e econômica e por nossos interesses. À primeira vista, portanto, uma missão impossível, já que um contrato social firmado diante de tais aspectos jamais seria justo. Foi diante de tais circunstâncias adversas que Rawls ${ }^{1}$ elaborou mecanismos de sustentação de sua teoria, que, segundo ele, buscam contraposição com as clássicas teorias do utilitarismo e do intuicionismo, que, por longo tempo, dominaram as tradições filosóficas.

Na introdução de seu trabalho, Rawls ${ }^{\mathbf{1}}$ apresenta as seguintes ponderações: 1) "a justiça é a primeira virtude das instituições sociais, assim como a verdade o é para os sistemas de pensamento" "(3); 2) as leis e as instituições, por mais eficientes e bem estruturadas que sejam, devem ser reformadas ou abolidas caso sejam injustas'; 3) todo indivíduo tem direito à inviolabilidade pessoal fundada na justiça, que não pode ser sobreposta nem mesmo para atender ao bem-estar de toda a sociedade, ou seja, não se concebe que o sacrifício imposto a alguns seja maior que a soma das vantagens obtidas pela maioria'; 4) "uma injustiça só é tolerável quando necessária a evitar uma injustiça ainda maior"1(4); 5) faz-se necessário, diante dos conflitos de interesse de uma coletividade, e em razão dos vários arranjos sociais possíveis, estabelecer princípios que propiciem uma justa distribuição de recursos'. Esses seriam os princípios de justiça social, capazes de estabelecer direitos e obrigações dentro da estrutura básica da sociedade, e de definir as bases da cooperação social na distribuição dos benefícios e ônus.

Como, então, definir princípios na estrutura básica de uma sociedade marcada por diversidades de toda sorte? Para possibilitar tal empreitada, Rawls ${ }^{\mathbf{1}}$ propõe o seguinte exercício mental: todas as pessoas seriam colocadas numa situação denominada 'posição original', que permitiria o estabelecimento de um procedimento justo de estipulação dos princípios a serem acordados. Para tanto, todos os indivíduos seriam colocados atrás do que ele chamou de 'véu da ignorância', que neutralizaria a tentação de cada pessoa de explorar os fatores sociais e naturais a seu favor. Se não pudesse conhecer como as várias alternativas poderiam afetar o seu caso particular, o indivíduo seria obrigado a avaliar os princípios com base apenas em considerações gerais, pois ninguém saberia sua posição na sociedade, suas habilidades e forças, condições psicológicas, as noções de bem, as particularidades de seu plano racional de vida. Também não saberia sua situação política ou qualquer particularidade da sociedade que ocuparia, como nível de evolução ou grau de desenvolvimento cultural. As pessoas na posição original não teriam informações acerca, sequer, da geração a que pertenceriam. A partir dessa situação de ignorância, bem como levando-se em conta que partiriam da mesma posição inicial, deveriam escolher princípios para os quais estivessem preparadas a aceitar as consequências, qualquer que fosse a situação em que viessem a ser colocadas na sociedade. Parte-se, portanto, da premissa de que todos conhecem apenas os aspectos gerais da sociedade, como as questões políticas, econômicas e as bases da organização social e das leis de psicologia humana, ou seja, presume-se que conhecem somente os fatores capazes de afetar a escolha dos princípios da justiça e a aceitação de suas implicações.

Do aludido contrato hipotético, Rawls idealiza o surgimento de dois princípios. $\mathrm{O}$ primeiro garantiria o máximo de liberdade básica igual a todos os cidadãos. O segundo, relativo a preocupações de igualdade social e econômica e subdividido em duas partes, prevê a possibilidade de existência de desigualdades relativamente aos bens primários básicos, 
desde que as diferenças sirvam ao benefício de todos (princípio da diferença), bem como estabelece direito de igual acesso a cargos e postos oficiais, os quais devem ser abertos a todos, em qualquer circunstância (princípio da oportunidade). Rawls ${ }^{1}$ afirma que sociedades e instituições somente são justas se pautadas por cada um desses princípios básicos, descritos originalmente da seguinte maneira:

Primeiramente: cada pessoa tem direito igual a mais extensa liberdade básica compatível com uma liberdade semelhante para os outros. Em segundo lugar: desigualdades sociais e econômicas devem ser dispostas de modo que sirvam tanto (a) como vantagem razoável a todos, e (b) ligadas a posições e cargos

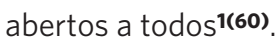

Posteriormente, Rawls ${ }^{4}$ muda, em alguns aspectos, o ponto de vista inicialmente apresentado na obra 'Uma Teoria da Justiça', a fim de tornar mais clara a redação dos princípios, bem como de alguns outros pontos obscuros do referido trabalho. A justiça como equidade teria sido elaborada para as instituições políticas, sociais e econômicas, portanto, não poderia ser entendida como uma concepção moral geral a ser aplicada à estrutura básica da sociedade. Sustenta, ainda, que no Estado moderno deve prevalecer a diversidade de doutrinas e o pluralismo de ideias, e que a justiça como equidade por ele defendida apresenta-se como uma alternativa ao utilitarismo e ao intuicionismo. Pondera que, nas democracias modernas, discussões acerca de direitos fundamentais, às vezes, parecem problemas sem solução. Quando isso ocorre, sugere que as questões sejam debatidas de modo a se encontrar uma resposta plausível, capaz de trazer algum consenso que, ainda que não ideal, seja ao menos razoável, baseada na cooperação política e no mútuo respeito.

Após a revisão dos princípios, estes, então, passaram a apresentar a seguinte redação:

Primeiro: cada pessoa deve ter um direito igual ao mais abrangente sistema de liberdades básicas iguais que seja compatível com um sistema semelhante de liberdades para as outras. Segundo: as desigualdades sociais e econômicas devem ser ordenadas de tal modo que sejam ao mesmo tempo (a) consideradas como vantajosas para todos dentro dos limites do razoável, e (b) vinculadas a posições e cargos acessíveis a todos ${ }^{4(64)}$.

Embora as alterações dos princípios não tenham sido significativas, o que ele buscou, principalmente com a mudança de redação do primeiro princípio, foi demonstrar que não se atribui prioridade às liberdades de forma geral e absoluta, como valor principal de um sistema político e social de justiça. O modo como justifica as liberdades básicas é um dos grandes diferenciais do liberalismo político de Rawls, que não defende um ideal moral abrangente, na forma preconizada pelos demais defensores do liberalismo ético-político. No tratado apresentado pelo filósofo norte-americano sobre os princípios da justiça, ele destaca que os dois princípios por ele defendidos consubstanciam um caso especial de uma concepção mais ampla de justiça ${ }^{4}$. Segundo ele, todos os valores sociais, tais como liberdade e oportunidade, renda e riqueza, e as bases do autorrespeito (que são para ele os bens primários sociais essenciais), devem ser distribuídos igualmente, a não ser que a distribuição desigual de um ou de todos esses valores seja feita para o benefício de todos. Para ele, portanto, injustiça é simplesmente desigualdade que não serve ao bem de todos ${ }^{4}$.

O princípio da diferença, de Rawls, preconiza que o tratamento desigual entre indivíduos tem um objetivo prático específico: compensar desigualdades e reduzir a distância social e econômica entre as pessoas. A busca da equidade pressupõe a existência de diferenças nas condições de vida dos indivíduos, e tais diferenças devem ser reduzidas mediante ações de políticas públicas e participação da sociedade.

Bobbio $^{5}$, ao tratar da igualdade das oportunidades, chama a atenção para o fato de que a 
vida é uma corrida ao alcance de bens escassos. Como em toda competição, se o ponto de partida é diferente para as pessoas, aquele cuja linha esteja mais à frente certamente vencerá a corrida. Por isso, defende a necessidade de igualdade dos pontos de partida, assim como a inclusão dos menos favorecidos. Ainda que se possa afirmar que as posições de partida variam de sociedade para sociedade, assim como Rawls, Bobbio ressalta que, para colocar pessoas desiguais por nascimento no mesmo ponto de partida é necessário favorecer uns em detrimento de outros.

Ainda que os escritos de Rawls não tenham sido específicos quanto à forma de diminuir desigualdades, sua teoria serviu de semente e de fundamento para ações políticas e sociais difundidas e aplicadas pelo mundo. As ações afirmativas no campo da educação, por meio da instituição de cotas, é um grande exemplo, já que cria uma igualdade, mediante a correção de uma desigualdade anterior.

\section{A teoria da justiça, de Rawls, aplicada à saúde}

Villas-Bôas ${ }^{6}$ reconhece que, embora a teoria de Rawls não seja voltada à saúde, é possível invocá-la, levando-se em conta a lista de bens primários por ele enumerados, em especial, o autorrespeito, que, além de envolver os demais bens, possui relação com a saúde e a integridade física, sem as quais fracassa o respeito à dignidade humana. A autora acredita que a teoria de Rawls, ainda que fundada em uma alegoria, é válida, na medida em que, diante de uma situação concreta, induziria ao equilíbrio entre interesse individual e coletivo. Reconhece que Rawls não é específico quanto aos mecanismos concretos de redistribuição, motivo pelo qual se faz necessária a estipulação de políticas e critérios de alocação orientados pelos princípios gerais da justiça, como equidade, plenamente conciliáveis com a ideia de justiça pela equidade, já que serviria de parâmetro para a identificação das desigualdades e a busca de mecanismos de compensação e de distribuição "que atenda(m) a uma igualdade de oportunidades e a uma discriminação positiva, quando necessária"6(154).

Mesmo que não pensada especificamente para a saúde, a teoria da justiça, de Rawls, marcada pelo princípio da diferença, levou, no campo da assistência à saúde, à instituição de sistemas de saúde criados sob as bases da universalidade de acesso e da equidade na distribuição de recursos escassos ${ }^{7}$. O Sistema Único de Saúde (SUS), por exemplo, possui forte viés rawlsiano, pois tem uma base igualitária e democrática fundada nos seguintes princípios e diretrizes: 1) universalidade de acesso em todos os níveis de assistência; 2) igualdade na assistência à saúde, sem distinções ou privilégios de qualquer espécie; 3 ) integralidade da assistência; 4) gratuidade; 5) participação da comunidade; 6) descentralização, regionalização e hierarquização de ações e serviços de saúde ${ }^{8}$.

Segundo Fortes ${ }^{7}$, alguns críticos apontam certa incongruência na aplicação da teoria de Rawls à saúde, sob a alegação de que se a distribuição de recursos escassos prioriza os mais pobres, não há que se falar em universalidade de acesso, pois os não tão pobres seriam empurrados para o livre mercado. Esse autor defende, no entanto, que, partindo-se do pressuposto de que a saúde é um bem primário e por todos desejada, o acesso a ela deveria ser, de fato, universal. Entretanto, se é direito de todos, mas limitada pela escassez dos recursos, aplicando-se o princípio da diferença, tem-se que $o$ acesso deveria ser priorizado aos menos afortunados, ou seja, "o princípio da diferença se aplicaria não às necessidades médicas, mas sim às necessidades sociais"7(110).

A teoria de justiça, de John Rawls, ainda que baseada em contrato hipotético e em situações ideais muitas vezes impossíveis, embasa a tomada de posições importantes no contexto social, principalmente no que diz respeito à correção de desigualdades, mediante a aplicação prática do princípio da diferença. Com efeito, verifica-se na teoria da justiça como 
equidade, de Rawls, uma preocupação com a prática de políticas sociais mais comprometidas com os vulneráveis.

Rawls define como bens primários as "coisas que todo homem racional presumivelmente quer"4(66), independentemente dos planos de vida de cada um. O papel das instituições seria distribuir, na base da sociedade e de forma justa, tais bens primários sociais. Além desses bens primários sociais, Rawls aponta a existência de bens primários naturais, entre eles, a saúde, o vigor, a inteligência e a imaginação. Com relação aos bens primários naturais, ele não se preocupou em definir sua escala de importância, a forma como deveriam ser tratados ou distribuídos pela sociedade, tendo se limitado a dizer que, "embora a sua posse seja influenciada pela estrutura básica, eles não estão sob seu controle de forma tão direta"4(66). Para o autor, é a partir do exercício de cidadania igual, "definida pelos direitos e liberdades exigidos pelo princípio de liberdade igual e pelo princípio da igualdade equitativa de oportunidades"4(102), que se avalia a estrutura básica da sociedade, e, embora haja assuntos que interessam a todos, os efeitos distributivos destes são irrelevantes. Aos bens primários naturais, portanto, aplicar-se-ia o que ele denominou "princípio do interesse comum"4(102), que seriam medidas eficientes, eficazes e sensatas adotadas pelas instituições a fim de que todos pudessem promover seus objetivos de forma semelhante, a partir de regras de interesse público capazes de "manter a ordem pública e a segurança ou medidas eficientes no setor de saúde e previdência social”4(103).

Embora Rawls tenha se esquivado de esmiuçar o alcance dos bens naturais, ao incluir os serviços de cuidados em saúde como um bem social, demonstrou abraçar a ideia de que as instituições devem proteger a saúde a fim de salvaguardar o leque de liberdades que sua teoria defende, assim como as oportunidades que as pessoas devem ter. A partir de uma interpretação extensiva do pensamento de John Rawls, Norman Daniels desenvolveu sua teoria de justiça em saúde, ressaltando que os cuidados em saúde têm o papel moral de garanti-la e, assim, proteger as liberdades e oportunidades de vida das pessoas. Para Daniels $^{2}$, a teoria de justiça de Rawls possui os elementos necessários para estabelecer uma distribuição equitativa de saúde, o que, a seguir, será desenvolvido.

\section{Norman Daniels - Ampliando a teoria da justiça, de Rawls}

Seria a saúde um direito fundamental do ser humano? A resposta para essa pergunta é hoje quase intuitiva e, mesmo, contundente: claro que sim! Por uma série de motivos, tal resposta faz certo sentido, por exemplo, em contraposição à perspectiva principialista que praticamente a interpreta como uma mercadoria, portanto, submissa às leis de mercado. Norman Daniels não concorda nem discorda, a princípio, de tal afirmação. Mas discorda de que seja esse o ponto de partida para uma construtiva reflexão acerca do que seja justiça em saúde². O simples apelo a um direito, por mais evidente que possa ser, não se sustenta. É preciso que haja uma fundamentação sólida que, ao mesmo tempo que fornece a base necessária, estabelece os limites desse direito, para não cairmos num 'buraco sem fundo' que engoliria toda e qualquer demanda de todos os indivíduos, fossem elas justas ou injustas ${ }^{2}$. Além disso, a consequência a um apelo a direitos individuais costuma cair na judicialização ${ }^{9}$, um mal a ser evitado.

O ponto de partida proposto por Daniels é o que ele chama de "pergunta fundamental"2(11): "O que devemos uns aos outros para promover a saúde numa população e dar assistência a pessoas doentes ou com algum tipo de deficiência?". Para responder a essa pergunta de forma satisfatória, ele a divide em outras três e especifica: 1- Teria a saúde um status moral especial?; 2- Quando são injustas as desigualdades em saúde?; 3- Como distribuir de forma justa os recursos em saúde? 
Quanto à primeira pergunta, Daniels ${ }^{2}$ acredita que sim, inferindo a partir do comportamento das pessoas que, mesmo admitindo distribuições desiguais de uma série de bens, quando se trata de saúde, costumam defender posições mais igualitárias. Cita, como prova disso, que existam, em seu próprio país - um país onde as desigualdades não são apenas toleradas, mas até mesmo positivamente mistificadas -, programas tais como o Medicare e o Medicaid, que procuram amenizar tais desigualdades para grupos socialmente mais vulneráveis (idosos e pobres, respectivamente) ${ }^{2}$. Apenas mais recentemente surgiu o chamado Obamacare, que trouxe alguns tímidos avanços nesse sentido.

Tendo a saúde, portanto, um status moral especial, é essencial protegê-la. Aqui, Daniels faz um mea culpa. O status moral especial não é de 'cuidados em saúde', mesmo que esses sejam tomados em seu sentido amplo, incluindo medidas em saúde pública, como ele havia desenvolvido em sua obra 'Just Health Care', de $1985^{2}$. O status moral especial é da saúde, tomado em sentido amplo o suficiente para incluir todos os seus potenciais determinantes sociais. Tal mudança de perspectiva torna ainda mais pertinente para Daniels sua opção por uma teoria da justiça pronta que se presta bem ao papel de fundamentação de sua própria: a teoria de John Rawls.

Considerando-se que os princípios de Rawls culminam na proteção das oportunidades das pessoas, e que estas necessitam estar com suas funções normais para exercerem plenamente suas oportunidades, segue-se que os princípios devam ser postos a serviço do bom funcionamento da sua saúde. Nesse sentido, Daniels ${ }^{2}$ lembra que sua teoria é uma extensão da de Rawls, pois este categoriza a saúde erroneamente como um "bem natural"2(13,21), simplificando sua escala de bens primários ao admitir "que todas as pessoas estarão plenamente funcionais em seu tempo de vida"2(56). Mesmo em sua obra posterior, na qual reviu alguns dos conceitos e posições de sua teoria original, Rawls ${ }^{4}$, ao mencionar a saúde, o faz de forma bastante restrita, referindo-se apenas aos cuidados de saúde requeridos quando alguém encontra-se em situação abaixo do mínimo necessário para exercer suas capacidades. A teoria de Daniels, ao colocar a saúde em seu sentido amplo e com status moral especial, a ser protegido pelos princípios de liberdade, diferença e igualdade de oportunidades, amplia e fortalece a teoria da justiça, de Rawls. A resposta à primeira pergunta, portanto, não chega a ser difícil ou controversa. O que dizer das duas seguintes?

Quando são injustas as desigualdades em saúde? Para responder a essa pergunta, Daniels ${ }^{2}$ retorna à sua premissa básica, de que a saúde tem status moral especial, não sendo apenas sinônimo de cuidados em saúde, mas, sim, abarca todos os seus determinantes sociais. Estes são bens primários, a serem assegurados a todos os indivíduos para que tenham como exercer amplamente suas oportunidades em seu tempo de vida. Nesse momento de sua obra, entretanto, Daniels trai seu viés epistemológico ao afirmar que há um hiato bioético nessa área, pois,

infelizmente, estas questões têm sido quase completamente ignoradas no campo da bioética, assim como no campo da ética e filosofia política em gera|2(82).

De acordo com ele ${ }^{2}$, a bioética não tem se dedicado às questões relativas aos "bens sociais que determinam a saúde das sociedades"2(81), e Amartya Sen seria a única exceção que ele é capaz de citar. Embora tal demonstração de desconhecimento ou ignorância da rica literatura em português, italiano e espanhol, e mesmo em inglês de autores de língua não inglesa (por exemplo, Garrafa e Porto ${ }^{10}$ ), chegue a ser constrangedora, o ponto de partida escolhido por Daniels não é de todo insatisfatório. A resposta à segunda pergunta pode, sim, ser de inspiração rawlsiana. A desigualdade em saúde será injusta sempre que impedir o pleno exercício das oportunidades da pessoa. E isso se dará sempre que um determinante social afetar o funcionamento normal dessa pessoa. $\mathrm{O}$ 
princípio da justiça como equidade, de Rawls, regula a distribuição dos principais determinantes sociais da saúde; portanto, é ele que fornece a base epistemológica para a construção de uma teoria da justiça em saúde.

Ainda que se possa questionar algumas premissas a partir das quais Daniels estabelece sua própria teoria, é preciso conceder que, em as aceitando, as respostas às duas primeiras perguntas são, de fato, satisfatórias. O mesmo não acontece com a terceira. Até porque, Daniels não chega a respondê-la. Como distribuir de forma justa os recursos em saúde? Certamente, não se trata de tarefa fácil. Ainda assim, quem se propõe a fazê-lo, que o faça. Ao rechaçar o utilitarismo e seus instrumentos, como as análises de custo-efetividade tipo QALY e DALY2, o que sobra é a possibilidade de priorizar os que estiverem em pior situação, a seguir a linha rawlsiana. Entretanto, tal caminho se revela rapidamente impraticável e, mesmo, injusto pela perspectiva da saúde pública. Daniels ${ }^{2}$ reconhece isso, propondo, então, alguns artifícios na tentativa de pelo menos se aproximar de uma resposta satisfatória. As decisões de alocação de recursos deveriam obedecer a um princípio de legitimidade que, por sua vez, obedeceria a quatro condições: publicidade, relevância, possibilidade de revisões e recursos, força regulatória.

A primeira condição que conferiria legitimidade aos agentes alocadores de recursos e suas decisões forçosamente limitadoras (por meio das quais sempre haverá ganhadores e perdedores) é a transparência. As regras, sejam quais forem, devem ser disponibilizadas publicamente. Em segundo lugar, tais regras devem ser razoáveis, ou seja, aceitas por todos os que sejam, eles próprios, pessoas razoáveis. A terceira condição é que sempre haja a possibilidade de se revisar ou mesmo questionar, por meio de recursos, as decisões tomadas, já que, seja lá qual for a regra escolhida, sempre pode ser circunstancialmente falha. Finalmente, tal regra precisa ter força regulatória para que as três condições anteriores aconteçam² ${ }^{2}$.

A impressão causada pela leitura do capítulo do livro de Daniels dedicado à terceira pergunta é a mesma deixada pelo parágrafo anterior. Qual regra? Afinal, se a teoria de Rawls não se presta a decisões de alocação de recursos em saúde pública, o que se adotará, então? Daniels não tem uma resposta para isso. Interessante notar que mesmo em palestras disponíveis na internet, posteriores à data de publicação de 'Just Health', ele continua não propondo nenhuma. E, igualmente interessante, num artigo dedicado exclusivamente a esse ponto específico da teoria de Daniels, Rid" ${ }^{n}$ faz crítica semelhante, sem, também, propor uma sua.

\section{Considerações finais}

Apesar das dificuldades em se definir o que é justo, a estipulação de critérios de justiça deve ocorrer desde a formação das bases de uma sociedade, mediante critérios estabelecidos por seus membros, num sistema de cooperação, respeito e benefícios mútuos. As teorias propostas por Rawls e Daniels propiciam a visão de que as escolhas sociais têm influência nas condições gerais de saúde, que é um valor a ser preservado e distribuído de forma compatível com o pluralismo moral, mediante políticas de alocação de recursos voltadas à eliminação ou redução das diferenças evitáveis entre os diversos grupos sociais.

Embora Rawls tenha tratado a saúde como um bem natural, e não social, e tenha evitado cuidar das iniquidades geradas pelas doenças e deficiências, Daniels esclareceu que o trabalho de Rawls sobre justiça distributiva apresenta suporte suficiente para o estabelecimento de uma conexão entre saúde e oportunidade, capaz de embasar a tese da existência de uma obrigação da justiça de proteger as oportunidades. Para Daniels, os princípios gerais de justiça de Rawls captam os elementos-chave dos determinantes da saúde, já que incluem os cuidados de saúde como bem primário das instituições.

A teoria da justiça, de Rawls, em especial o segundo princípio (que engloba os princípios da diferença e da oportunidade), tem 
relevância e repercussão nas discussões acerca de justiça social, da saúde pública, guardando uma certa interface com as chamadas bioéticas latino-americanas, em que a noção de responsabilidade social envolve a necessidade de proteção pública e estatal dos mais vulneráveis ${ }^{\mathbf{1 2}}$. Em Daniels, foi reforçado o papel da saúde como bem primário garantidor de oportunidades. Além disso, o autor teve o mérito de rever suas ideias iniciais quanto à justiça na saúde e reconhecer que a equidade não se restringe ao acesso, mas, numa sociedade justa, deve levar em conta pelo menos os determinantes sociais da saúde.

A concepção de justiça como equidade, a partir da obra de Rawls e Daniels, seria aquela que, além de garantir o exercício das liberdades básicas, asseguraria a todos, de forma equânime, a distribuição dos bens primários essenciais, compensando-se, sempre que possível, as loterias biológicas e sociais. Assim, conclui-se que a ideia de justiça como equidade, de Rawls e Daniels, não é outra senão aquela que garante que o exercício das liberdades assegura a todos, de forma ponderada, a distribuição de bens primários sociais essenciais, inclusive a saúde.

Apesar de não apresentarem uma resposta mais ampla e definitiva sobre como distribuir recursos de forma justa, as teorias de Rawls e Daniels remetem a reflexões sobre a necessidade de se reduzir injustas desigualdades em saúde, bem como suscitam debates sobre questões como cooperação social, liberdades, as bases da igualdade, alocação de recursos escassos, distribuição adequada de rendas e riquezas e de oportunidades. De modo geral, pode-se afirmar que as teorias de justiça, de Rawls e Daniels, possibilitam avanços teórico-práticos, contribuindo positivamente para o enfrentamento de problemas associados às políticas de acessibilidade e de justa distribuição de recursos no campo da saúde pública.

\section{Colaboradores}

Paranhos DGAM contribuiu para a realização do planejamento, concepção e elaboração do texto, revisão crítica do conteúdo e versão final do manuscrito. Matias EA contribuiu em parte para o conteúdo e a versão final do manuscrito. Monsores $\mathrm{N}$ contribuiu para a concepção do estudo, orientação da pesquisa, revisão crítica e aprovação da redação final. Garrafa V contribuiu para a orientação do projeto, concepção do estudo, revisão crítica e aprovação da redação final. 


\section{Referências}

1. Rawls J. A theory of justice. USA: The Belknap press of Harvard University press; 1971.

2. Daniels N. Just Health: meeting health needs fairly. New York, Cambridge: Cambridge University Press; 2008.

3. Rawls J. Justiça como equidade: uma concepção política, não metafísica. Lua Nova: 1992; 25:25-59.

4. Rawls J. Uma Teoria da Justiça. São Paulo: Martins Fontes; 2000.

5. Bobbio N. Igualdade e liberdade. Rio de Janeiro: Ediouro; 2002.

6. Villas-Bôas ME. O Direito à Saúde no Brasil - reflexões bioéticas à luz do princípio da justiça. São Paulo: Edições Loyola; 2014.

7. Fortes PAC. Como priorizar recursos escassos em países em desenvolvimento. In: Garrafa V, Pessini L, organizadores. Bioética: Poder e Injustiça. São Paulo: Edições Loyola; 2004. p. 103-112.

8. Noronha JC, Lima LD, Machado CV. O Sistema Único de Saúde - SUS. In: Giovanella L, Escorel S, Lobato LVC, et al, organizadores. Políticas e sistema de saúde no Brasil. Rio de Janeiro: Fiocruz; 2014. p. 365393.

9. Daniels N. The Right to Health at the Public/Private Divide [vídeo]. Edited by Aeyal Gross and Colleen Flood Book Discussion; 2015 [acesso em 2018 nov 19]. Disponível em: https://www.youtube.com/ watch?v=3Gq5QmXJ-sk.

10. Garrafa V, Porto D. Intervention Bioethics: A Proposal for Peripheral Countries in a Context of Power and Injustice. Bioethics. 2003; 17(5-6):399-416. [acesso em 2018 nov 19]. Disponível em: https://onlinelibrary.wiley.com/doi/10.1111/1467-8519.00356.

11. Rid A. Justice and procedure: how does "accountability for reasonableness" result in fair limit-setting decisions? J Med Ethics. 2009; 35:12-16.

12. Garrafa V, Cunha TR, Manchola C. Access to healthcare: a central question within Brazilian bioethics. Cambridge Quarterly Healthcare Ethics. jul 2018; 27(3): 431-439

Recebido em 10/06/2018

Aprovado em 07/10/2018

Conflito de interesses: inexistente

Suporte financeiro: não houve 